\title{
A bibliometric overview of WMU Journal of Maritime Affairs since its inception in 2002
}

\author{
Satya Sahoo ${ }^{1} \cdot$ Alessandro Schönborn $^{2}$
}

Published online: 16 March 2020

(C) World Maritime University 2020

\begin{abstract}
This article provides a reflection on the original aims of WMU Journal of Maritime Affairs (JOMA) and its achievements over its 17 years of existence. JOMA has been a central medium for research and international dialogues for issues relating to the global maritime field. It has pursued a philosophy of aiming to provide a wide range of professionals in the maritime fields and to offer a fair representation of various research areas and to promote interdisciplinarity in research. JOMA has evolved in a rapidly changing world of maritime affairs, which witnesses major global challenges on the horizon, as represented by the need for the UN 2030 Agenda for Sustainable Development. Bibliometric analyses were used in this article to examine the research output from JOMA in terms of citations, geographic distribution of authorships, and research areas. The 'moving average of annual citation ratio' is adopted as a tool to analyse its output and impact on various research areas published in JOMA since its beginning.
\end{abstract}

Keywords Bibliometric overview, Maritime journals, VOSviewer

\section{Introduction}

The WMU Journal of Maritime Affairs (henceforth called as JOMA) was founded with the aim of providing a central medium for research and international dialogue for issues relating to the global maritime field. It was in recognition of a need to internationally consolidate maritime research as a distinct field of study. In the year 2002, WMU

Satya Sahoo

srs@wmu.se

Alessandro Schönborn

as@wmu.se

1 Shipping and Port Management, World Maritime University, Malmö, Sweden

2 Maritime Energy Management, World Maritime University, Malmö, Sweden 
developed its first research agenda under Dr. Karl Laubstein, in its ambition to progress from a training institution to a research led higher education institution. With the ambition for WMU to become a global centre of excellence in maritime research, an instrument of continuous discussion on maritime issues was needed. The Journal was aimed to be interdisciplinary in nature and firmly anchored in real issues of the industry, so as to remain accessible to a wide range of professionals ranging from maritime administration, industry, and academia. The articles published in JOMA originally covered an interdisciplinary field comprising the subject's maritime safety, marine environment protection, and shipping operations, with particular focus on the human element and the impact of technology.

The broad range of topics covered by JOMA is a reflection of the interdisciplinarity defining the maritime field. The inauguration of the WMU-Sasakawa Global Ocean Institute in May 2018 market the due entwinement of ocean issues with the maritime field. Issues such as climate change, loss of biodiversity, and pollution of the oceans form an inherent link maritime and oceans research. As the awareness between the link of human activities and environmental issues grows, the intersection of oceans research and the maritime field naturally becomes an ever more essential part of the maritime field, and it is expected to grow in its importance for the Journal.

It is its specialisation in international maritime issues, and its dedication to interdisciplinarity, that have allowed JOMA to serve the international community of maritime professionals in administrations and industry. This issue of the Journal aims to analyse the mission, past achievements, the progressive development of the maritime research field, and contents covered by JOMA, and to reflect and identify a future path forward for its mission.

\section{Research methods}

\subsection{Principle}

The bibliometric analyses and identification of future directions of WMU Journal of Maritime Affairs were conducted with the principle in mind that this Journal takes a holistic approach to the maritime field. The Journal's philosophy is to give a fair representation of all subject areas in the maritime field and to offer a voice to all stakeholders. Maritime research is, of course, evolving with time, and its journal should be able to reflect the urgency of the issues at hand. The aim of this bibliometric analysis is to explore the strategic directions in which the WMU Journal of Maritime Affairs should move in the future and to investigate ways in which the direction of the journal can be used to follow the natural course of development of the maritime sector. Notwithstanding the journal is dedicated to a holistic approach and we will not be tempted into directing its focus exclusively at an individual subject of current interest or let an individual subject fully take over the focus of the journal.

\subsection{Bibliometric analysis}

The bibliometric analyses conducted in this study comprised the total number of articles published in JOMA, during its 17 years of existence, and its citations. The 
number of citations that JOMA articles received, the articles which JOMA cited, and JOMA's co-citations were analysed using data available on Google Scholar.

In addition to these analyses, the types of articles published in JOMA were classified according to WMU's research priority areas (RPAs) in the maritime field $^{1}$. Since JOMA is a journal covering a number of research areas, it is important for its editor to define the extent to which certain research areas should be represented within the journal. In order to provide some analytical support with this task, the ability of each of JOMA's RPAs to producing citations was analysed using the 'Citation Efficiency Factor' defined as the number of citations per year divided by the number of publications published in the journal per year. This analysis covered a time span of recent years to provide an indication of which areas of research should now receive further particular emphasis for development, and which may be reduced in their coverage.

\section{Results and discussion}

\subsection{Publications and citations}

JOMA published the first issue of volume 1 in April 2002. The first article published in the Journal was "Maritime safety: To be or not to be proactive" by Psaraftis (2002). Since 2002 until November 2019, JOMA has published 325 articles with on average 18-20 articles published annually. Seen over the entire duration of its existence, the number of articles published in JOMA has been slowly but steadily increasing over the years. Figure 1 presents the number of articles published per year and the cumulative number of citations. The bibliographic analysis does not include the complete data for 2019, which is why the number of articles published in 2019, and the number of citations in 2019, appears to be lower. Figure 1 shows that over the years JOMA has been allowed to grow at a relatively steady pace.

According to Google Scholar, the total of 325 articles published at JOMA has received 2614 citation cumulatively by the end of November 2019. Figure 1 shows that the annual number of citations has been gradually increasing over time, indicating the increasing impact of the journal. The average number of annual citations received by JOMA (for the year 2017 and 2018) is 331.50. In this context, it is of interest to look further into which types of works published in JOMA are most frequently cited, and which topics or areas of research these works represent. Section 3.2. provides a bibliographic analysis of the most cited papers, and those that have received the most citations per year, on average.

\footnotetext{
${ }^{1}$ In recognition of the pressing international issues being defined by the UN Sustainable Development Goals (SDGs) adopted as part of the 2030 Agenda for Sustainable Development by all UN Member States, WMU defined, in 2015, its research priority areas (RPAs) in the maritime field as (i) Environmental Impact of Maritime Activities, (ii) Maritime Economics and Business, (iii) Maritime Law Policy and Governance, (iv) Maritime Safety, (v) Maritime Energy Management, (vi) Maritime Social and Labour Governance, (vii) Maritime and Marine Technology and Innovation, and (viii) Maritime Education and Training.
} 


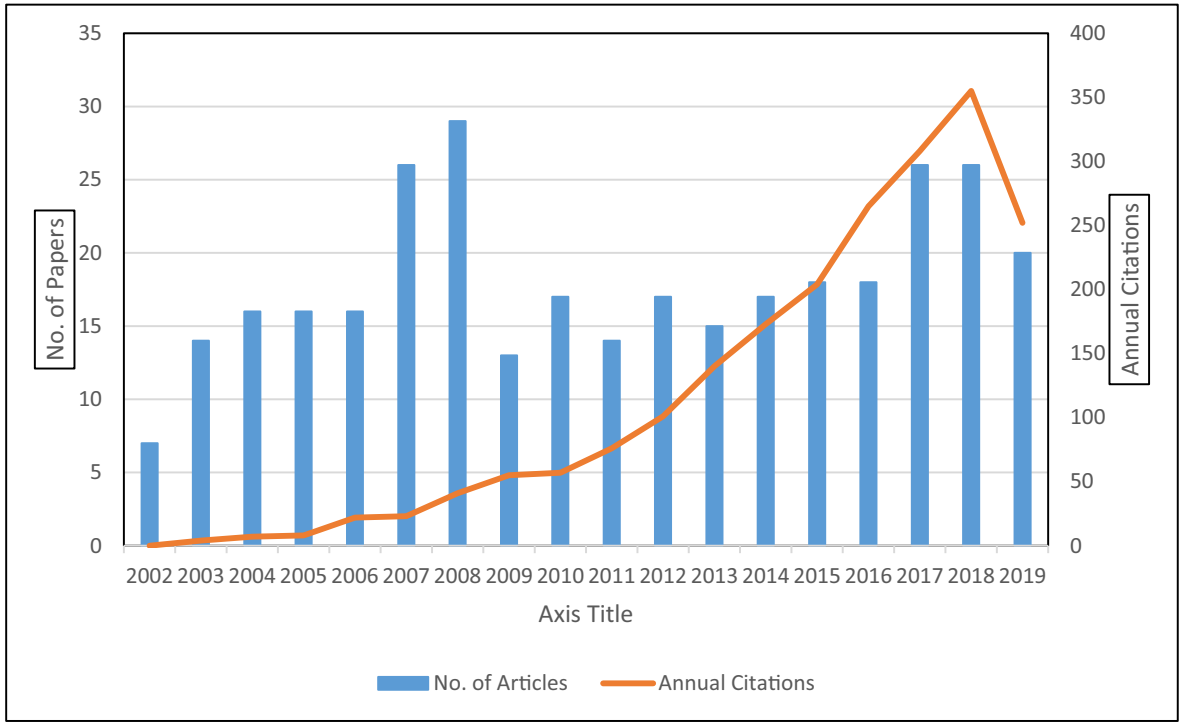

Fig. 1 Annual number of articles published and cited. Note: The data is only until November 2019

\subsection{Influential papers in JOMA journal}

The number of citations gives a simple indication of how influential a paper is in the research field. Table 1 shows the ten most cited papers of JOMA during its 17 years of existence. The article titled " $\mathrm{CO}_{2}$ emission statistics for the world commercial fleet" by Psaraftis and Kontovas (2009) has received the highest number of citations by other works, with a total of 175 . The topic of this paper is one relating to a prominent topic of our time, the amount of $\mathrm{CO}_{2}$ emitted from the use of energy from the world's commercial shipping fleet. The paper titled "Modeling the risk of ship grounding - a literature review from a risk management perspective" by Mazaheri et al. (2014) is the youngest paper in the list of top 10 most influential papers by JOMA, showing a high potential for increasing its number of citations in the coming years. This paper is a review paper on risk modelling in maritime safety.

Maritime safety is the most highly represented subject in this table, representing 4 out of the ten most-cited JOMA papers. As will be shown in section 3.4. of this article, maritime safety is the most frequent topic to which JOMA papers belong and may be viewed as one of the most important, if not the most important, subjects of JOMA since its creation. The metrics provided in Table 1 provide information about which papers have received most citations since they were published. This measure of the influence of a paper naturally favours older papers, since it allows these to collect a higher amount of citations over the years. To provide a measure that tries to take into account the shorter amount of time available for recently published papers to collect citations, a list of the ten papers that has received the highest average annual citations as shown in Table 2.

Table 2 presents the list of top 10 papers that receive the highest average annual citations. The most cited paper " $\mathrm{CO}_{2}$ emission statistics for the world commercial fleet" by Psaraftis and Kontovas (2009) also received the highest number of about 16 average 
annual citations per year. It is also interesting to observe that 7 of the top 10 fastest cited papers (in Table 2) are also the top 10 most cited papers in JOMA (presented in Table 1). This suggests that those articles which received the highest number of citations did so within a relatively short amount of time.

\subsection{Global visibility: co-cited journals and countries}

As the official journal of the World Maritime University, it is of utmost importance that JOMA represents scientific and technical quality, and achieve global visibility as a central medium for research and international dialogue. Figure 2 presents the top journals that have cited JOMA's publications. As a journal that is only 17 years old journal, JOMA has proven its ability to fulfill this role from its very onset. JOMA has been able to gain citations from other top maritime journals and to attract global researchers to submit and publish articles in various interdisciplinary subsectors of JOMA, within the maritime and ocean fields.

Figure 2 shows that JOMA has been most cited by the three journals Marine Policy, Maritime Policy and Management, and Safety Science. This emphasizes the strength which JOMA has in WMU's RPAs of Maritime Law Policy and Governance, Maritime Social and Labour Governance, and Maritime Safety, as an influence in other journals, underlines JOMA tradition in these fields. Other Journals citing JOMA include Ocean Engineering and Energy Policy representing more technical journals also associated with the RPAs Maritime and Marine Technology and Innovation and Maritime Energy Management. The journals Sustainability..., Journal of Cleaner Production, and

Table 1 Top 10 most cited papers

\begin{tabular}{|c|c|c|c|c|}
\hline Rank & Year & Title & Authors & No. of citations \\
\hline 1 & 2009 & $\begin{array}{l}\mathrm{CO}_{2} \text { emission statistics for the world } \\
\text { commercial fleet }\end{array}$ & $\begin{array}{l}\text { HN Psaraftis, CA } \\
\quad \text { Kontovas }\end{array}$ & 175 \\
\hline 2 & 2012 & $\begin{array}{l}\text { From Titanic to Costa Concordia-a century } \\
\text { of lessons not learned }\end{array}$ & $\begin{array}{l}\text { JU Schröder-Hinrichs, } \\
\text { E Hollnagel }\end{array}$ & 110 \\
\hline 3 & 2003 & The human element in shipping & WA O’Neil & 80 \\
\hline 4 & 2011 & $\begin{array}{l}\text { The impact of low sulphur fuel requirements } \\
\text { in shipping on the competitiveness of roro } \\
\text { shipping in Northern Europe }\end{array}$ & T Notteboom & 71 \\
\hline 5 & 2008 & A statistical overview of ship recycling & NE Mikelis & 68 \\
\hline 6 & 2012 & $\begin{array}{l}\text { Market-based measures for greenhouse gas } \\
\text { emissions from ships: a review }\end{array}$ & HN Psaraftis & 68 \\
\hline 7 & 2011 & $\begin{array}{l}\text { Dealing with multicultural human resources in } \\
\text { a socially responsible manner: a focus on } \\
\text { the maritime industry }\end{array}$ & M Progoulaki, M Roe & 67 \\
\hline 8 & 2014 & $\begin{array}{l}\text { Modeling the risk of ship grounding - a litera- } \\
\text { ture } \\
\text { review from a risk management perspective }\end{array}$ & $\begin{array}{l}\text { A Mazaheri, J Montewka, } \\
\text { P Kujala }\end{array}$ & 65 \\
\hline 9 & 2005 & Goal-based standards & H Hoppe & 51 \\
\hline 10 & 2014 & $\begin{array}{l}\text { Maritime safety and the ISM code: a study of } \\
\text { investigated casualties and incidents }\end{array}$ & BM Batalden, AK Sydnes & 51 \\
\hline
\end{tabular}


Table 2 Top 10 Fastest Cited Papers

\begin{tabular}{|c|c|c|c|c|}
\hline Rank & Year & Title & Authors & $\begin{array}{l}\text { Avg. annual } \\
\text { citations }\end{array}$ \\
\hline 1 & 2009 & $\begin{array}{l}\mathrm{CO}_{2} \text { emission statistics for the world } \\
\text { commercial fleet }\end{array}$ & HN Psaraftis, CA Kontovas & 15.80 \\
\hline 2 & 2012 & $\begin{array}{l}\text { From Titanic to Costa Concordia - a century } \\
\text { of lessons not learned }\end{array}$ & $\begin{array}{l}\text { JU Schröder-Hinrichs, } \\
\text { E Hollnagel }\end{array}$ & 14.14 \\
\hline 3 & 2014 & $\begin{array}{l}\text { the risk of ship grounding - a literature review } \\
\text { from a risk management perspective }\end{array}$ & $\begin{array}{l}\text { A Mazaheri, J Montewka, } \\
\text { P Kujala }\end{array}$ & 11.80 \\
\hline 4 & 2012 & $\begin{array}{l}\text { Market-based measures for greenhouse gas } \\
\text { emissions from ships: a review }\end{array}$ & HN Psaraftis & 8.86 \\
\hline 5 & 2014 & $\begin{array}{l}\text { Maritime safety and the ISM code: a study } \\
\text { of investigated casualties and incidents }\end{array}$ & BM Batalden, AK Sydnes & 8.60 \\
\hline 6 & 2016 & $\begin{array}{l}\text { Blue growth and ocean governance- }- \text { how to } \\
\text { balance the use and the protection of the seas }\end{array}$ & P Ehlers & 8.33 \\
\hline 7 & 2011 & $\begin{array}{l}\text { The impact of low sulphur fuel requirements } \\
\text { in shipping on the competitiveness of roro } \\
\text { shipping in Northern Europe }\end{array}$ & T Notteboom & 8.25 \\
\hline 8 & 2011 & $\begin{array}{l}\text { Dealing with multicultural human resources in } \\
\text { a socially responsible manner: a focus } \\
\text { on the maritime industry }\end{array}$ & M Progoulaki, M Roe & 8.00 \\
\hline 9 & 2016 & Barriers to energy efficiency in shipping & H Johnson, K Andersson & 7.33 \\
\hline 10 & 2014 & $\begin{array}{l}\text { Using the flipped classroom to improve student } \\
\text { engagement and to prepare graduates to meet } \\
\text { maritime industry requirements: a focus on } \\
\text { maritime education }\end{array}$ & $\begin{array}{l}\text { AJ James, CKH Chin, } \\
\text { BR Williams }\end{array}$ & 6.40 \\
\hline
\end{tabular}

Marine Pollution Bulletin show JOMA's influence and dedication to topics related to the RPA Environmental Impact of Maritime Activities. Citations in the journals like

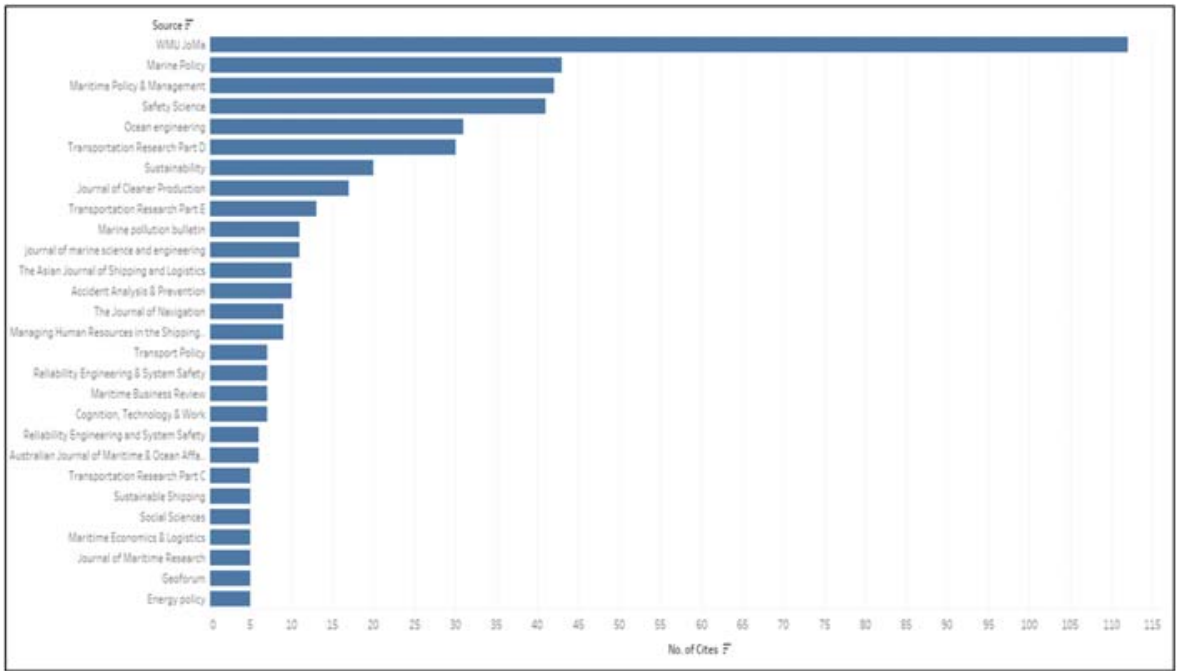

Fig. 2 Top 30 journals citing JOMA articles (2002-2019) 


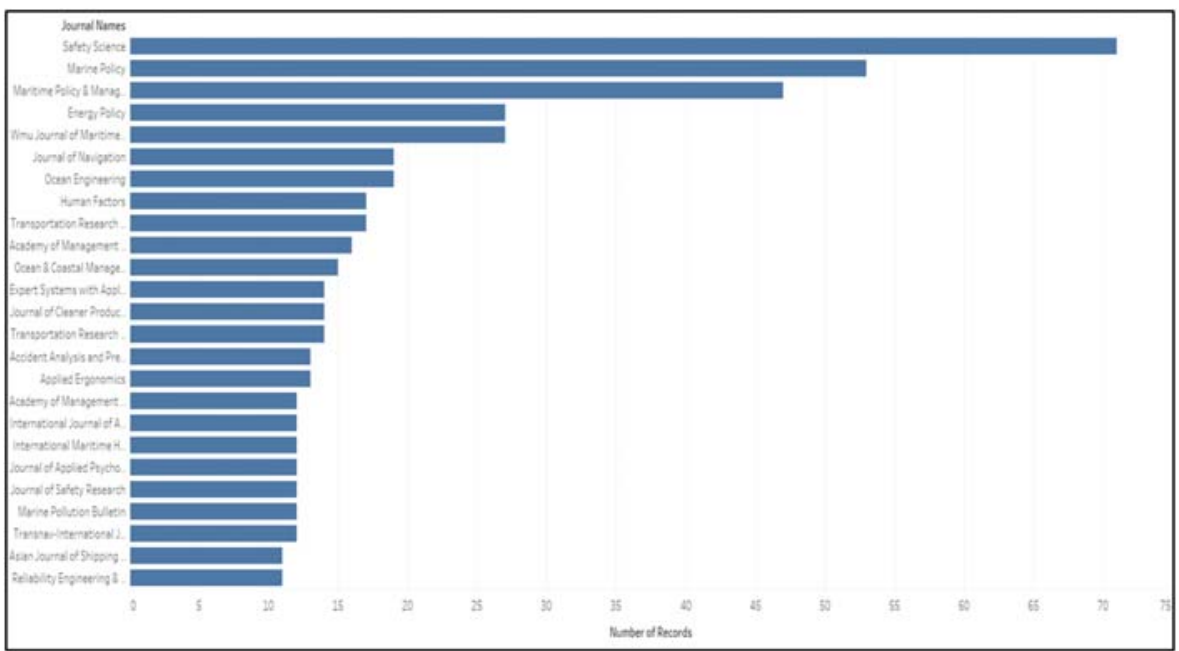

Fig. 3 Top 25 journals cited by JOMA papers (2015-2019)

Human factors, Applied Ergonomics, and Journal of Applied Psychology, show JOMA's focus on human factors, while citations are shown in Fig. 2 for Transportation Research series of journals (Part A, Part B, Part E, etc.) show

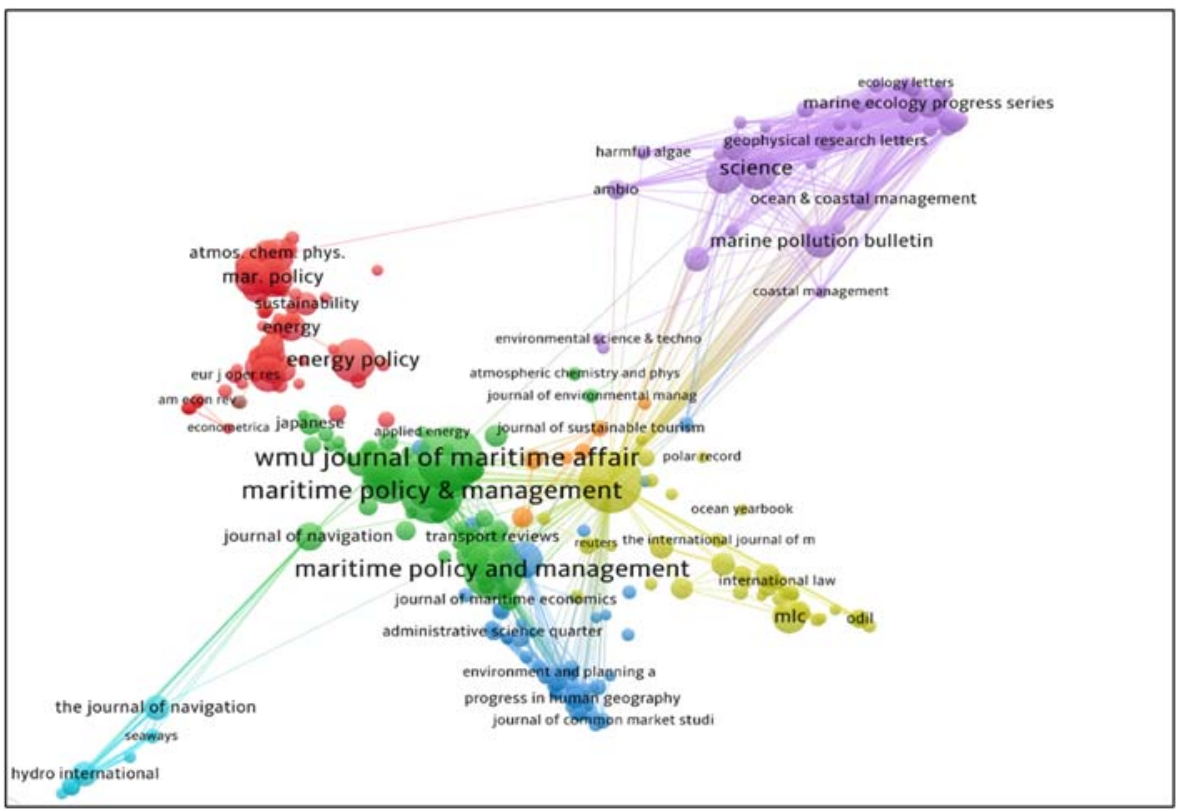

Fig. 4 Co-citation of JOMA with other journals. Note: The green circles' reference to core maritime related journals, violate circles indicate science and technology journals, yellow indicates law journals citing JOMA articles, and the red circles refer to JOMA articles cited in policy, sustainability, and energy journals (Please note that some of the journals like Maritime Policy and Management are repeated twice as in some citations it is referenced as Maritime Policy and Management while in others as Maritime Policy \& Management. Since we are only using names of journals of journals used in various citations, we encounter this issue) 
JOMA's influence in the RPA Maritime Economics and Business. Citations in Ocean and Coastal Management are representative of JOMA influence in Ocean research.

The interaction between JOMA and several other international journals in various fields can also be shown by examining the journals which JOMA cites in its article. The journals most cited by JOMA are shown in Fig. 3.

Figure 3 shows that the journals Safety Science, Marine Policy and Maritime Policy and Management are the journals most cited in JOMA. These are identical to the top three journals citing JOMA, previously shown in Fig. 2, underlining the strong link of influence between these journals, and the importance of the RPAs of Maritime Law Policy and Governance, Maritime Social and Labour Governance, and Maritime Safety for JOMA. The link between various topics can further be evaluated by assessing the number of co-citations between JOMA and other journals. Co-citations are defined as the frequency with which JOMA articles and articles found in other journals are cited together by a third source. This analysis was done using bibliometric data registered on Google Scholar and was visualised in Fig. 4.

Figure 4 shows the interaction of JOMA with various journals in terms of the occurrence of co-citation. Co-citation is the citation of JOMA articles together with those of other journals, in a third text. Figure 4 represents the frequency of co-citation with other articles using the size of the spheres with which the other journals are represented. Self-citations were included in this graphic, which is why JOMA itself is present in the graph. The distance between the various journals was defined according to how different the various journals are in terms of their topics. Two journals covering two closely related topics were placed close to one another, while two journals covering fundamentally different topics were located far from each other. All journals were

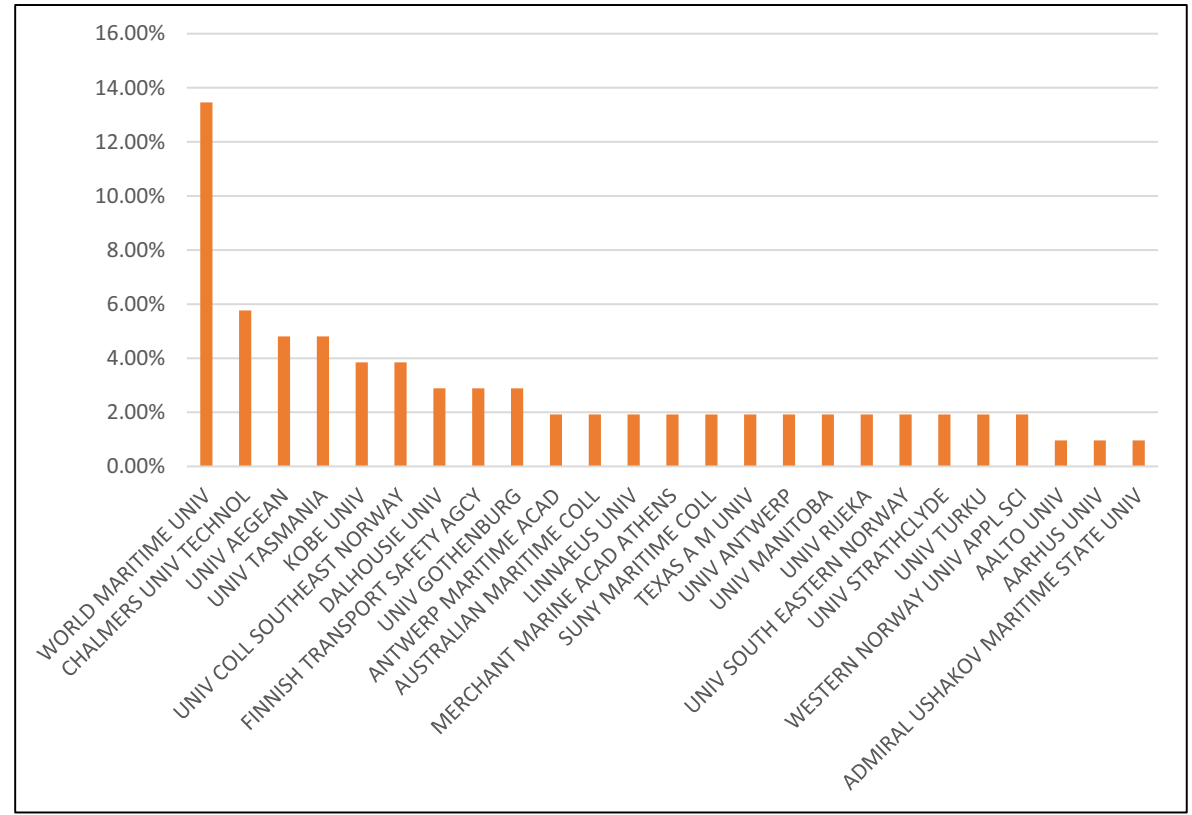

Fig. 5 Top 25 institutes publishing in JOMA (2015-2019) 


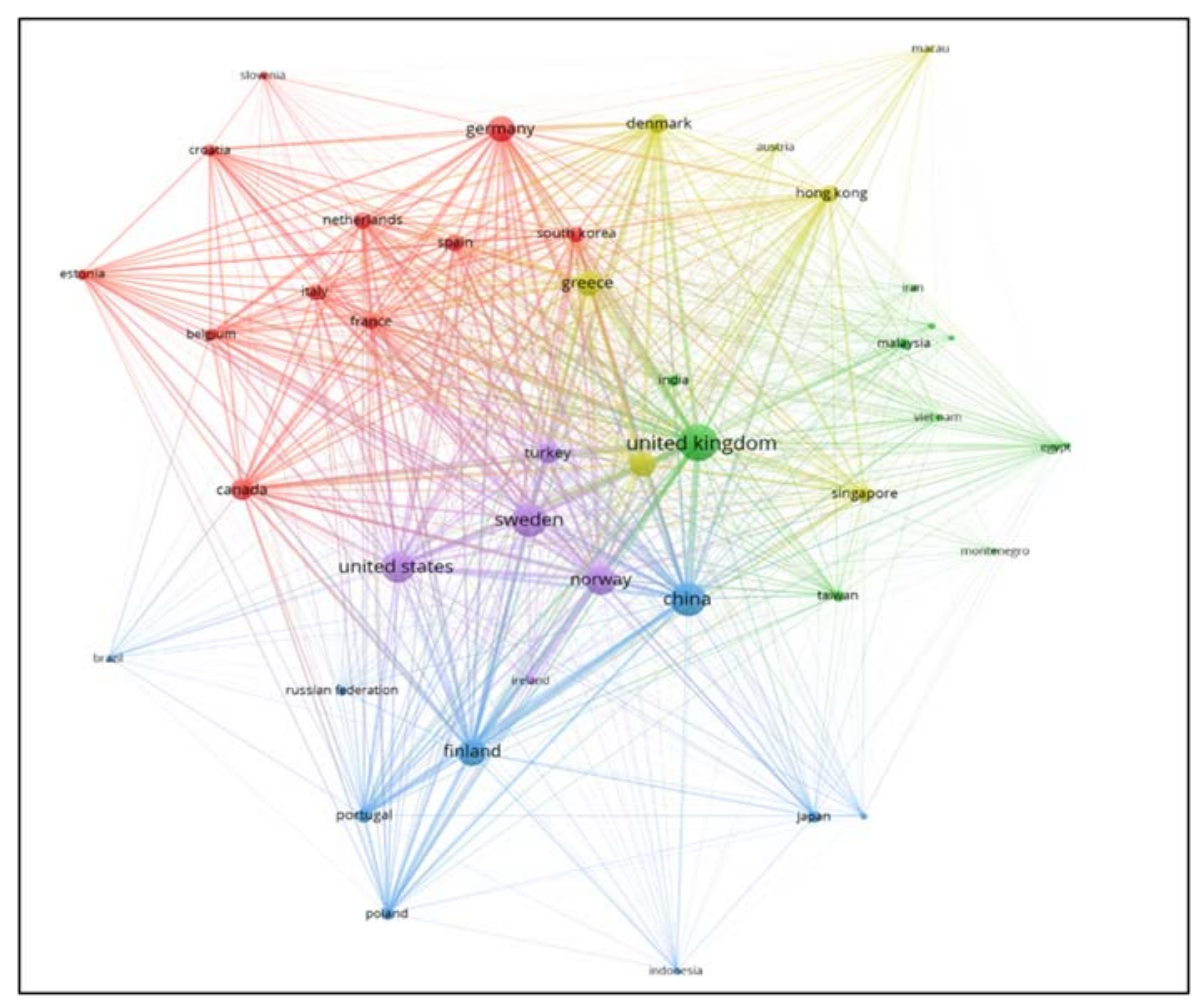

Fig. 6 Bibliographic coupling of countries publishing in JOMA. Note: Red circles represent mainly European countries, while blue circles indicate mainly Asian countries. Other coloured circles represent mixed co-authors papers published in JOMA

colour coded into five individual journal groups covering the topics: Energy, Marine Science, Maritime Issues, Navigation, Economics, and Policy and Law.

The data in Fig. 4 shows that the most co-cited journal of JOMA is the journal Maritime Policy and Management, which covers some closely related issues. Significant co-citation also existed with the journals Marine Policy and Energy Policy addressing policy issues. Co-citation was also prominent for the marine science journals Marine Science and Marine Pollution Bulletin as well as for the economics journals Journal of Maritime Economics and Progress in Human Geography. A high number of co-citations were also found for the navigation journals Journal of Navigation and Hydro International. The co-citations shown in Fig. 4 illustrate the complicated interaction of policy and governance with science, technology, and economics.

JOMA was created to provide a global platform for dialogue and discussion of global issues in the maritime field. As WMU's official journal, its global representation and impact have been a key requirement and quality for the journal. The global representation and interest in JOMA can be illustrated when looking at the diversity of the 25 most frequent affiliations of JOMA's authors (Fig. 5). Contributors are affiliated with a large and diverse range of geographic locations, reaching from Chalmers University sharing WMU's own host country of Sweden, to the University 


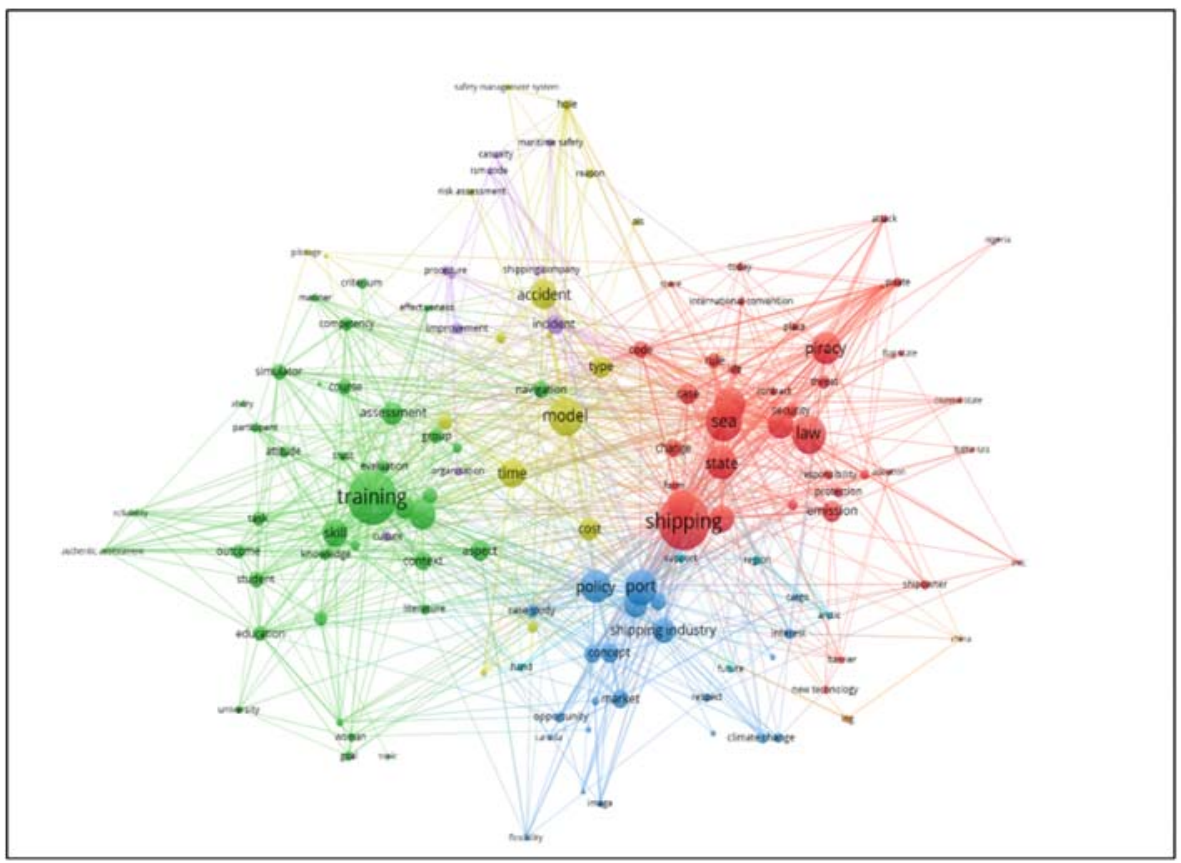

Fig. 7 Co-occurrence of author's keywords. Note: Red circles represent shipping and law and administrative related articles, green circle represents maritime education, and training, blue circles indicate ports and policy related articles, and yellow represents accidents and policy related articles.

of the Aegean in Greece, The University of Tasmania in Australia, Kobe University in Japan, Dalhousie University in Canada, State University of New York Maritime College in the USA, and Admiral Ushakov Maritime State University in Russia. It is

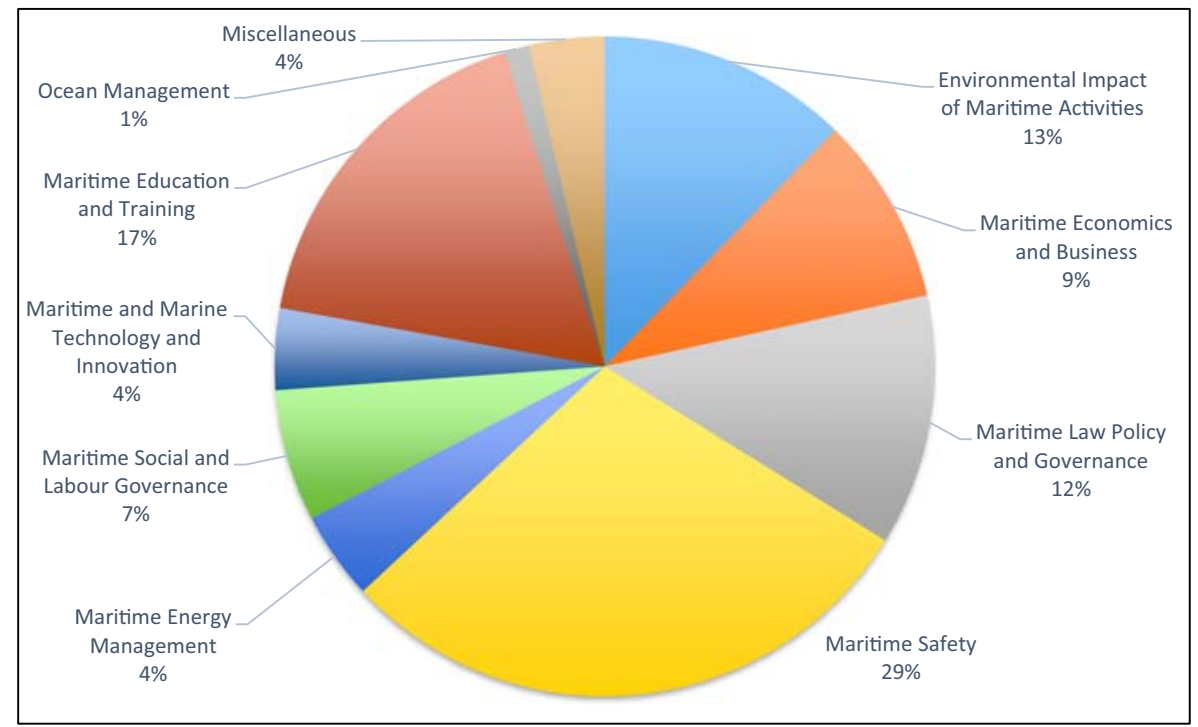

Fig. 8 Published articles areas (2002-2019) 


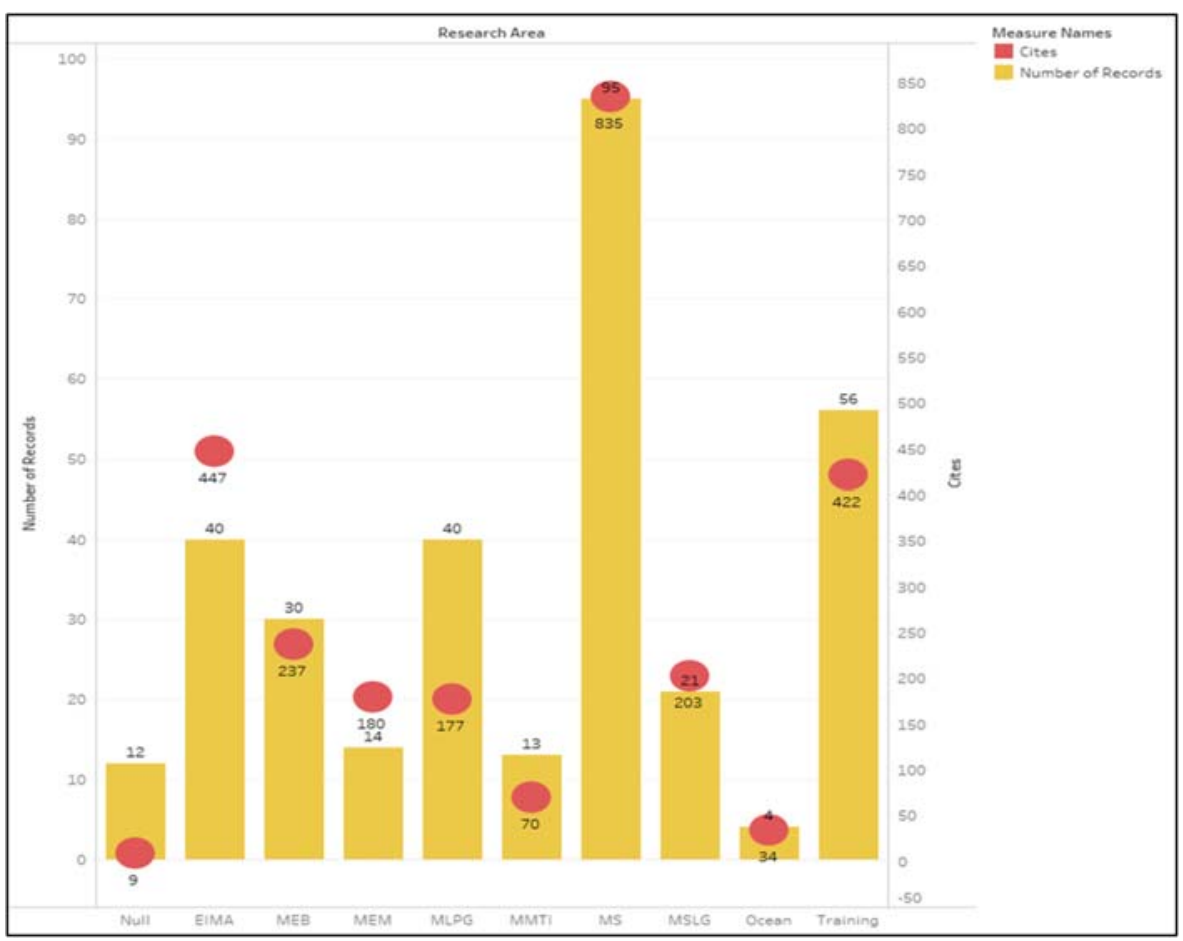

Fig. 9 Number of citations vs. number of publications (as per RPAs). Note: Null indicates miscellaneous articles

hoped that this broad representation of authors in JOMA and the worldwide interest in the journal can be further developed in the future to further improve the representation of the global maritime field.

The geographic distribution of institutions publishing in JOMA has been analysed according to the location of their host institution, in order to get a clearer overview of the geographic coupling of authorship. Figure 6 shows a graphic representation of the authors of JOMA articles. The size of the sphere is proportional to the fraction of authors from a particular country. The highest number of contributions was made by authors with host institutions located in the UK, followed closely by contributions from Sweden, the USA, China, and Norway. Further contributions include countries from Asia, Africa, Europe, North America, and South America.

\subsection{Subject areas addressed}

An insight into the subject areas covered by JOMA was assessed using the frequency of co-occurrence of article keywords found in JOMA articles. The keywords were ranked by frequency of their occurrence, and the relationship amongst them was examined according to the frequency with which these were cited together. Figure 7 shows the frequency of keywords occurring in JOMA articles, representing keywords with a higher frequency of occurrence by larger spheres and less frequent keywords by smaller spheres. The distance between keywords was inversely proportional to the frequency with which keywords were cited together. 
Figure 7 shows the frequency of keywords of JOMA articles, showing shipping, training, sea, law, policy, port, piracy, skill, cost, and market as the ten most frequent keywords. These ten most frequent keywords are representative of the five RPAs: Maritime Economics and Business (MEB), Maritime Education and Training (MET), Environmental Impact of Maritime Activities (EIMA), Maritime Law Policy and Governance (MLPG), Maritime Safety (MS). The remaining three RPAs are less but still visibly represented. For instance, Maritime Social and Labour Governance (MSLG) is clearly represented by keywords such as organisation, culture, woman, competency, responsibility, and casualty. The RPA Maritime Energy Management (MEM) is also visibly represented by terms such as climate change and emission, as is the RPA Maritime and Marine Technology and Innovation (MMTI), by the term new technology. Figure 8 presents the percentage of publication in the aforementioned areas between 2002 and 2019.

In order to analyse the topics covered by JOMA in some more detail, the entirety of JOMA's articles published so far were categorised according to their respective RPA. The fraction of articles represented by each area of research calculated and is presented in Fig. 8. As shown in Fig. 8, JOMA published the highest fraction of papers in the area
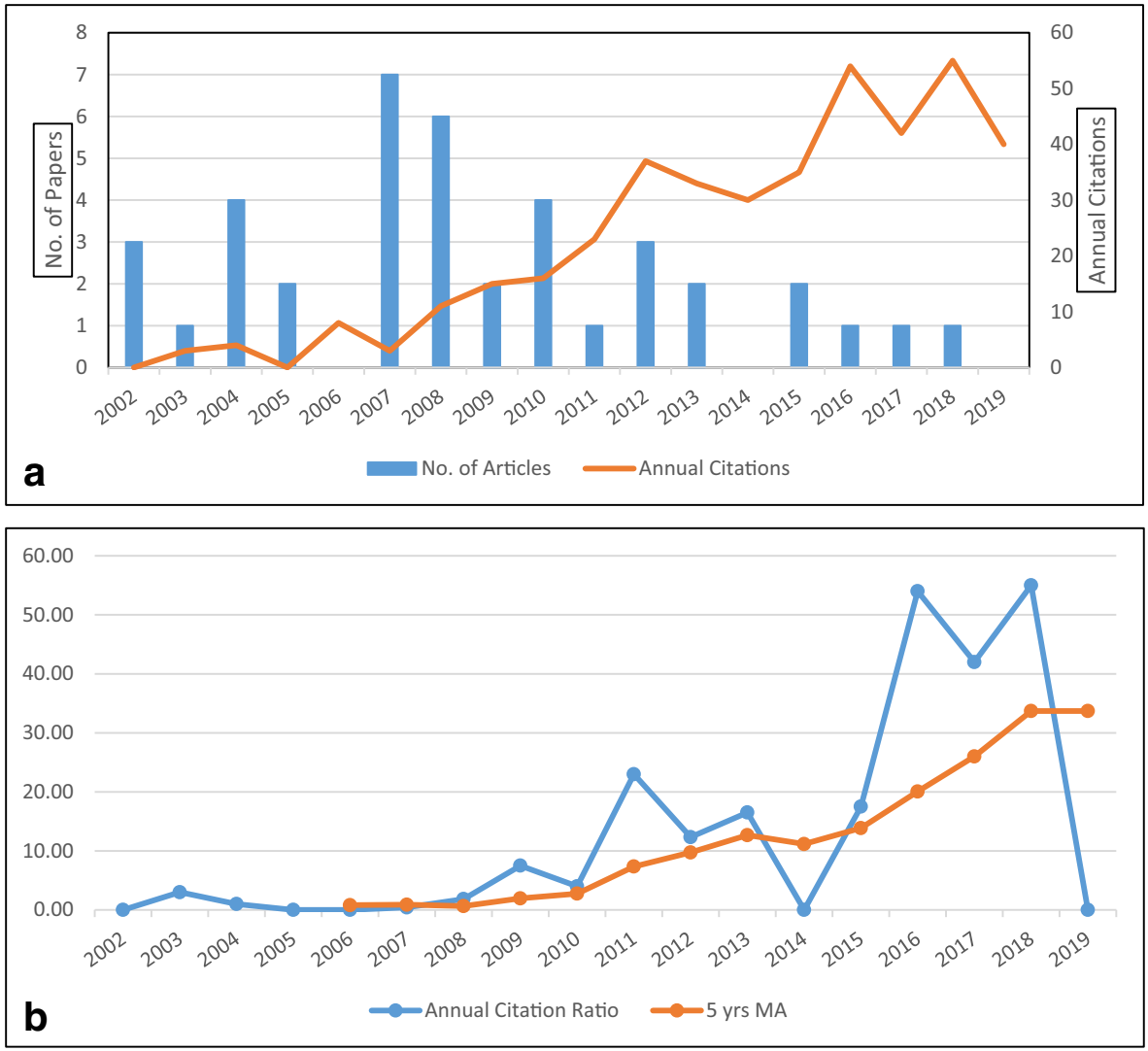

Fig. 10 a No. of articles published and annual citations for EIMA articles. b Annual citation ratio and 5-yearmoving average for EIMA articles 
of Maritime Safety (about 29\%), which has traditionally been one of the main areas of interest of JOMA. Maritime safety is followed by Maritime Education and Training (about 17\%), Maritime Law, Policy and Governance (about 12\%), and Environmental Impact of Maritime Activities (about 12\%). These four RPAs cover more than $71 \%$ of all JOMA articles together. Apart from the three major areas, JOMA also active in publishing articles related to Maritime Economics and Business, Maritime Social and Labour Governance, Maritime Energy Management, Maritime and Marine Technology and Innovation, and Ocean Management.

Certain areas such as Ocean Management and Maritime Energy Management are areas growing, given the growing pressure on issues such as loss of biodiversity and climate change, and these areas would be expected to grow to some extent in the coming years. It is the philosophy of JOMA to provide a fair and holistic representation of the maritime field and that no single area should take over or totally dominate. Yet, it may be of interest to identify which areas within the maritime field are underrepresented in terms of the impact and citations that they produce when compared with the number of articles published within JOMA in this particular field. To this end, the JOMA 'Citation Efficiency Factor' was developed as a tool to indicate future directions for JOMA.
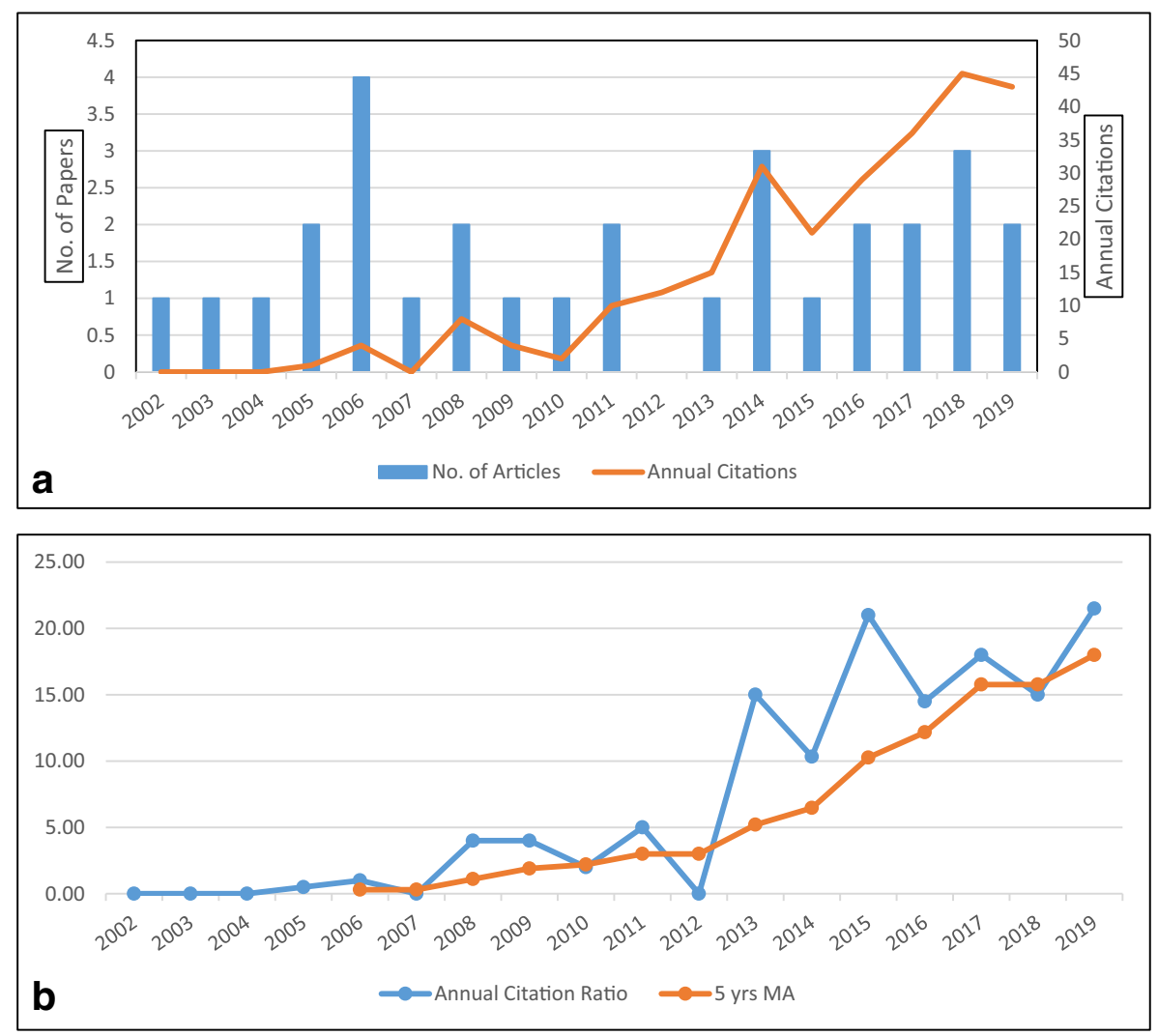

Fig. 11 a No. of articles published and annual citations for MEB articles. b Annual Citation Ratio and 5-YearMoving Average for MEB Articles 
Figure 9 shows the total historical number of articles published within each RPA, as well as their respective cumulative number of citations. Maritime Safety has by far the highest number of articles published, at 835, and also shows a suitable number of citations at 95. This main RPA is thus represented fairly in terms of citations, in relation to the number of works published in this area. Other areas, such as Environmental Impact of Maritime Activities, may be seen as underrepresented in terms of the number of articles published in this area, compared with the number of citations it has produced. This may be viewed as a strategic area of expansion for JOMA, given its comparatively high impact. Similarly, Maritime Energy Management and Maritime Social and Labour Governance have been comparatively underrepresented in JOMA, given their impact in terms of citations, and maybe a suitable area to which JOMA may dedicate more attention to in future volumes.

\subsection{Time-varying citations in each research priority areas (RPAs)}

The citations received by the articles in each research area might change over time. Hence, it is interesting to investigate the number of citations received in each research
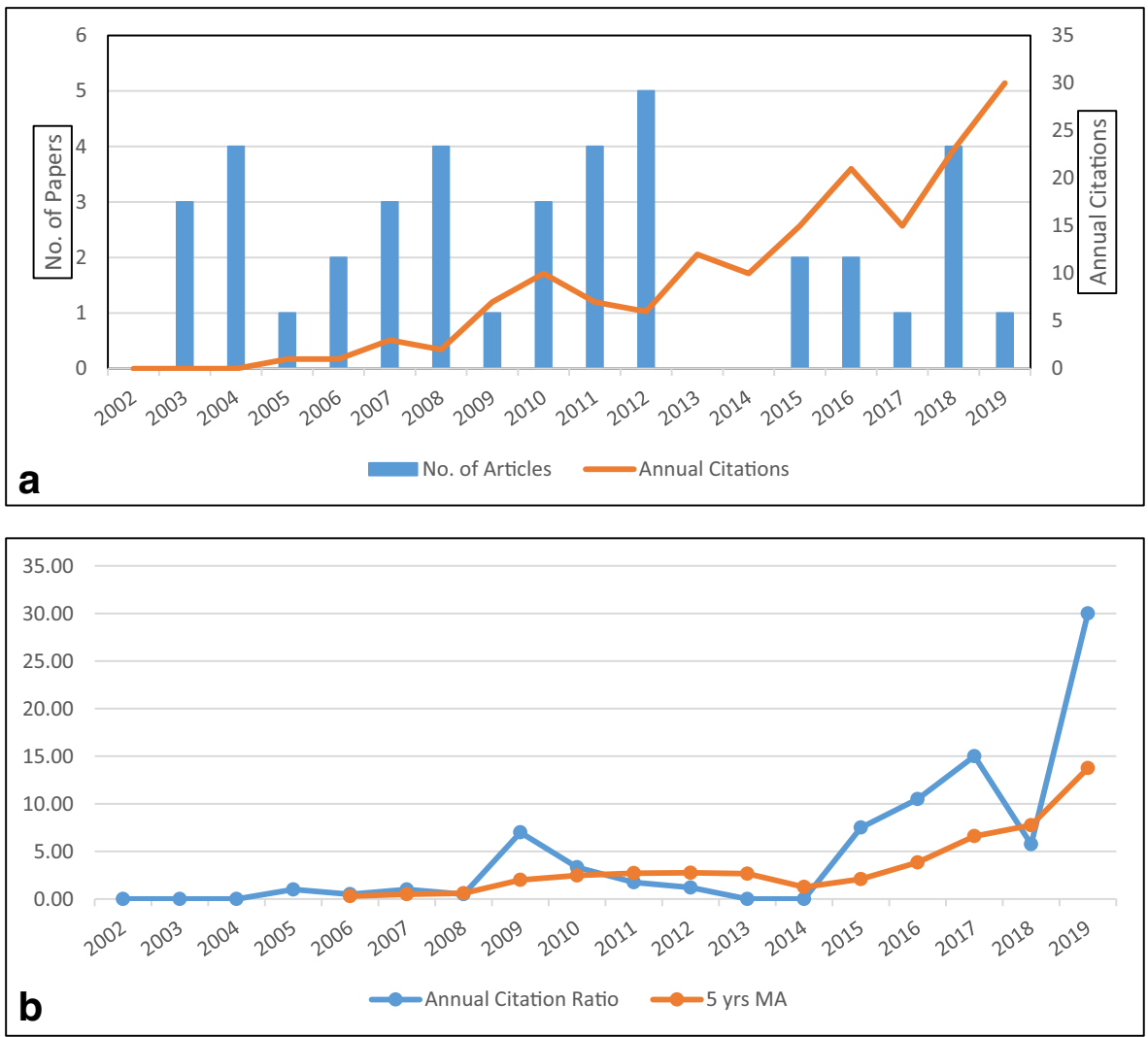

Fig. 12 a No. of articles published and annual citations for MLPG articles. (b) Annual Citation Ratio and 5Year-Moving Average for MLPG Articles 

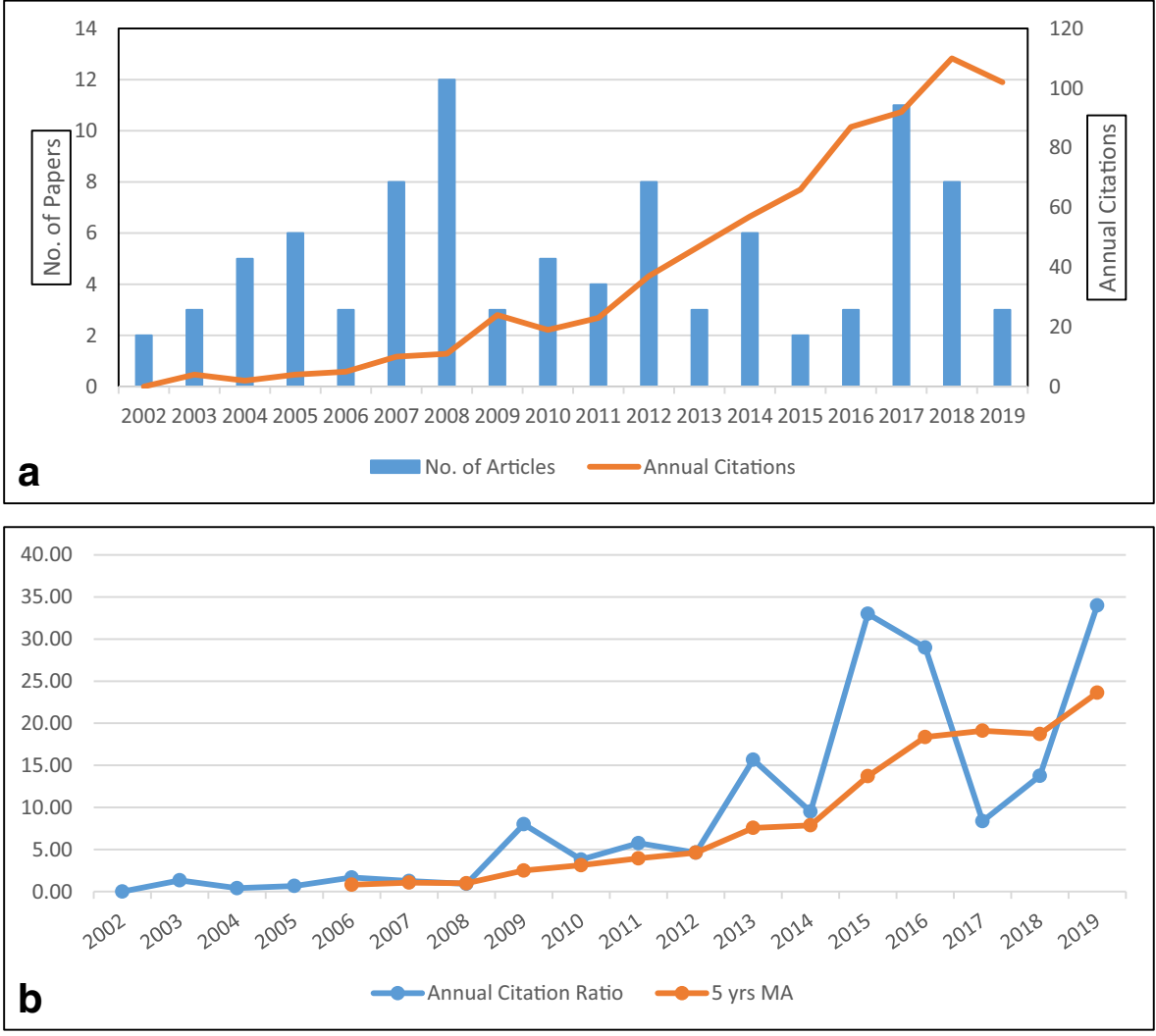

Fig. 13 a No. of articles published and annual citations for MS articles. (b) Annual citation ratio and 5-yearmoving average for MS articles

area of JOMA articles over time. This section presents how the citations associated with each research priority area have changed over time.

Figure $\mathrm{XXa}^{2}$ presents the number of articles published and the number of citations received in each research area. Observing only the number of articles publish and annual citations received in each subject area might be very intuitive to understand which area is gaining more citations annually, essentially indicating which area is becoming more attractive for researchers, we breakdown the data to annual citation ratio.

$$
\text { Annual Citation Ratio }=\frac{\text { Annual Citations }}{\text { No.of articles published }}
$$

Where the annual citations refers to the number of citations received by all the articles published in a years and the no. of articles published refers to the number of articles published in that subject area in the corresponding year.

\footnotetext{
$\overline{{ }^{2} \text { Where XX takes value between }} 10$ to 17 .
} 

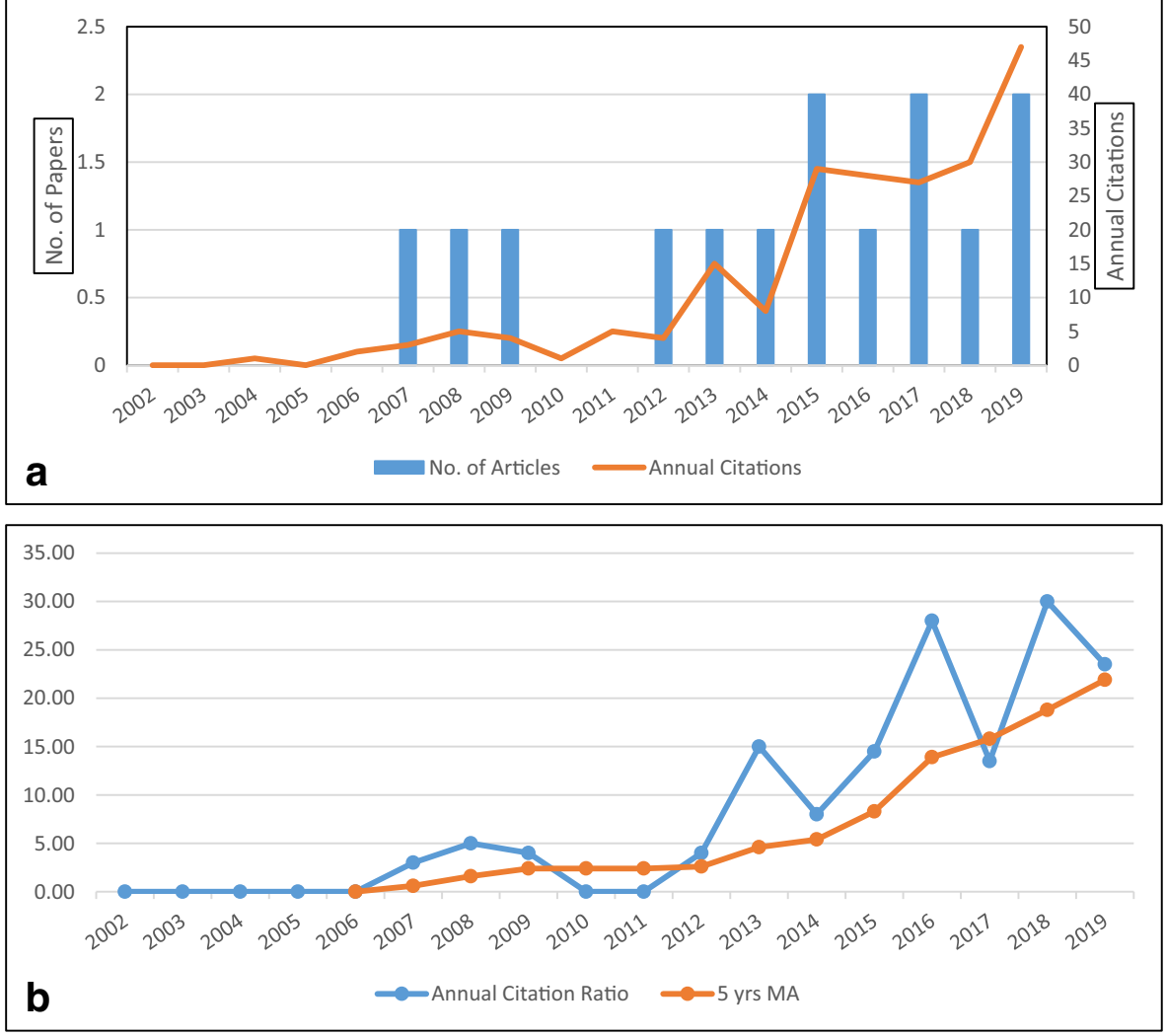

Fig. 14 a No. of articles published and annual citations for MEM articles. (b) Annual citation ratio and 5-yearmoving average for MEM articles

The annual citations ratio parameter can be quite fluctuating over time as a particular subject area could receive high/low number of citations each year, it is sensible to observe the moving average of the annual citations ratio instead of the absolute value only. In this case, we have considered five years moving average of the annual citations ratio. Figure $\mathrm{XXb}^{3}$ presents the annual citations ratio and the five years moving average of the annual citations ratio.

As observed in Fig. 10, JOMA was actively publishing in the area of Environmental Impact of Maritime Activities between 2007 and 2010; however, there is a decline in the number of publications in this area since then. Nevertheless, the number of citations received in the EIMA area is constantly increasing.

Figure $10 \mathrm{~b}$ indicates that even though there is a fluctuating annual citation ratio, the five years moving average of the annual citation ratio is constantly increasing, indicating that there are active interests of author(s) publishing and citing JOMA articles in the area of EIMA.

Figure 11a indicates that JOMA continuously publishes articles related to Maritime Economics and Business. Further, the annual citation received for MEB area is also

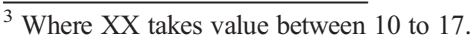



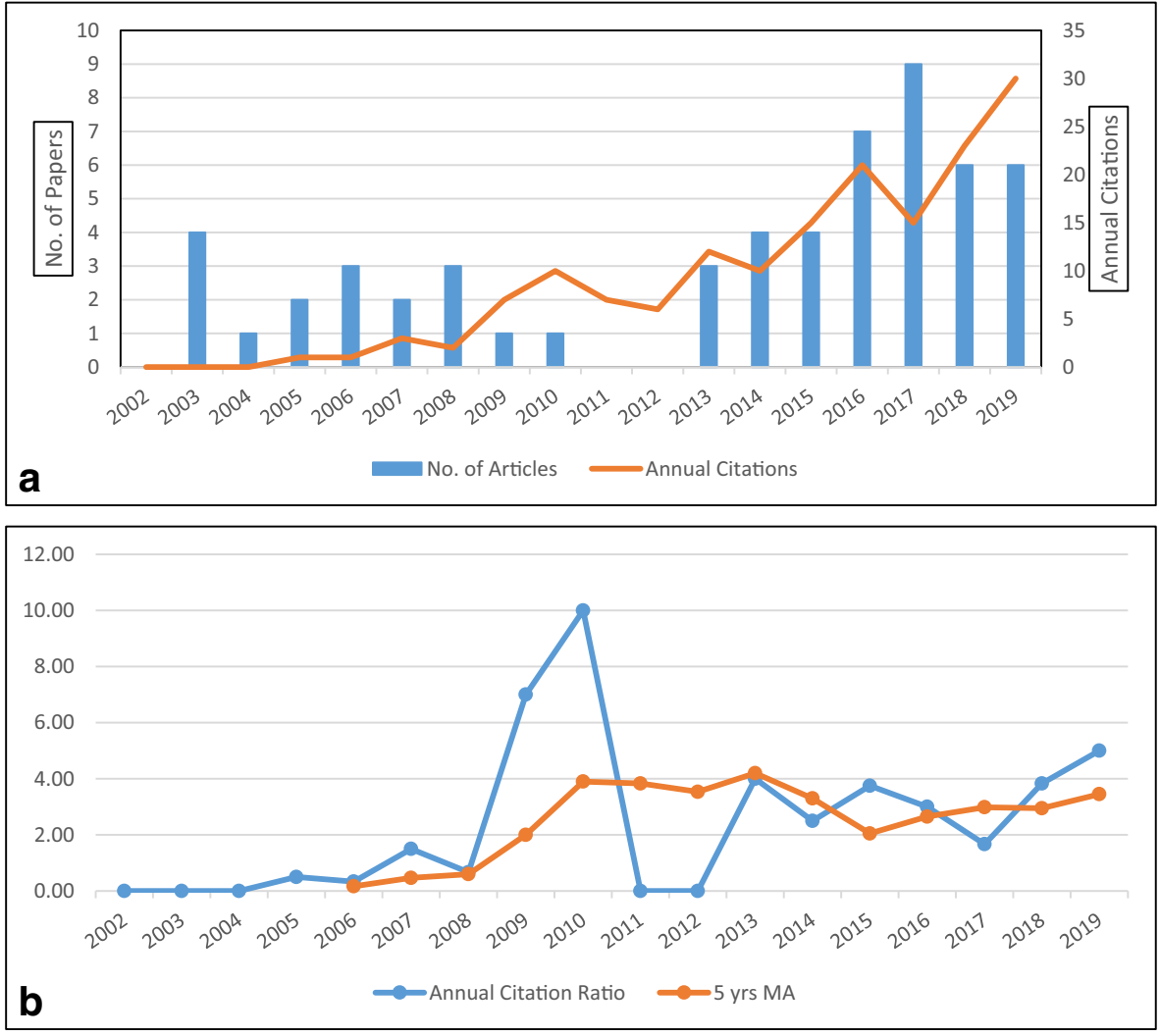

Fig 15 a No. of articles published and annual citations for MSLG articles. b Annual citation ratio and 5-yearmoving average for MSLG articles

constantly increasing, which indicates that there are active readers of the maritime economics and business articles published in JOMA.

Also, it is observed that the moving average of the annual citation ratio has constantly been increasing since 2006, indicating that there is active interest by authors to cite the maritime economics and business articles published at JOMA (Fig. 11b).

Figure 12a indicates that JOMA was actively publishing articles related to Maritime Law Policy and Governance until 2012, after which there is a decline in the number of articles published. Never the less, the number of citations received for the corresponding articles published is increasing over time.

Figure $12 \mathrm{~b}$ indicates that the annual citation ratio and its moving average for this area is low over time which also indicates that the MLPG articles published in JOMA are not attracting academic readers.

Figure 13a indicates that there is a cyclical trend in the number of Maritime Safety articles published in JOMA with the highest number of maritime safety articles published in 2008 and the lowest in 2015. However, JOMA has always been active in publishing articles related to Maritime Safety. Also, annual citations of these articles published in JOMA have constantly increased over time. 

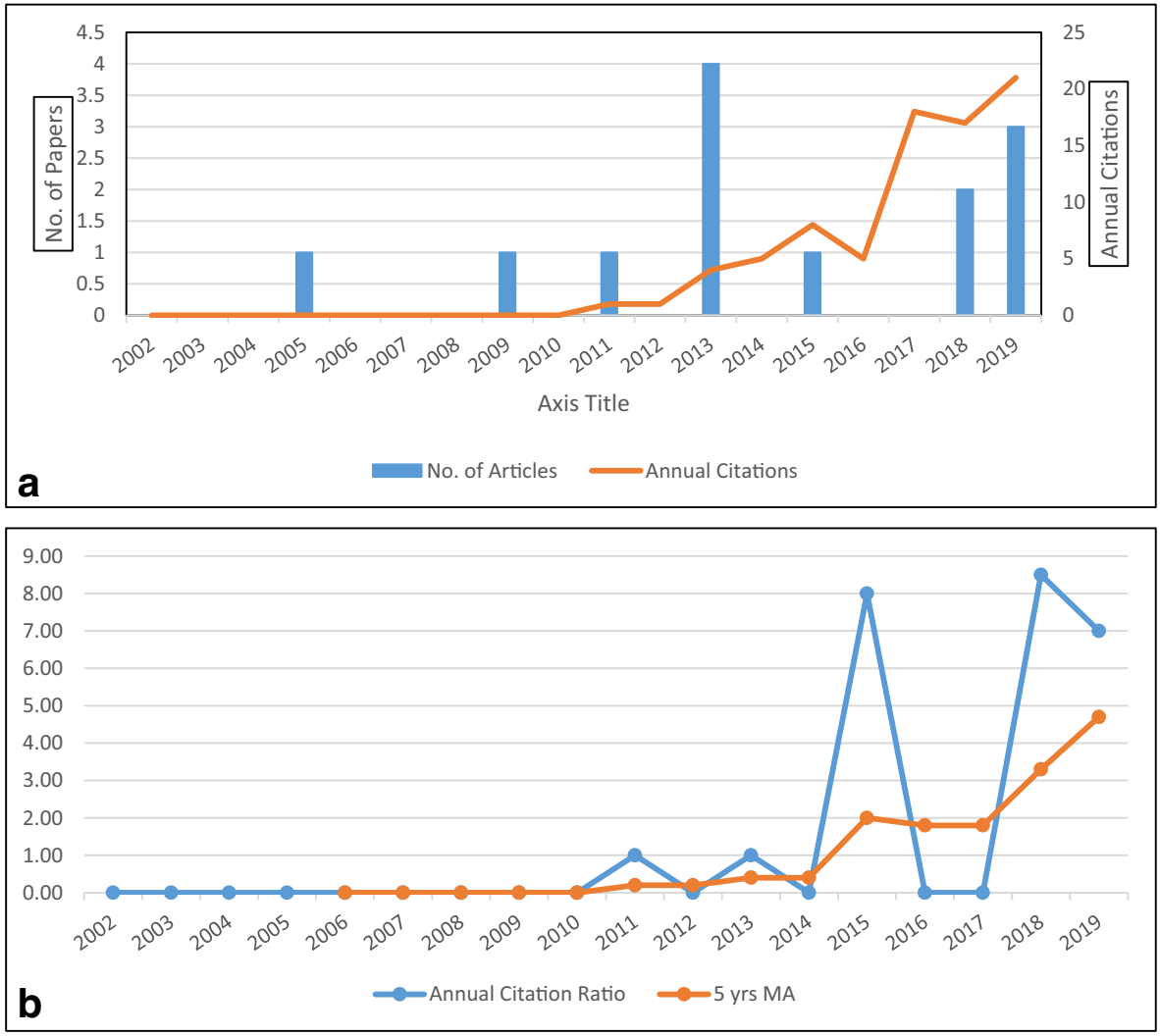

Fig 16 a No. of articles published and annual citations for MMTI articles. b Annual citation ratio and 5-yearmoving average for MMTI articles

Figure $13 \mathrm{~b}$ indicates that even though there are fluctuations in the annual citation ratio for MS articles published at JOMA, the moving average of the annual citation ratio always indicates an increasing trend. It indicates that there is active interest for researchers to read and cite maritime safety related articles published in JOMA.

There is a growing awareness of clean fuel and environmental sustainability in the maritime industry which developed interests in publishing Maritime Energy Management related articles in JOMA in recent years. The annual citation of MEM related articles published in JOMA was low before 2012, but has been increasing since then (Fig. 14a). Also, as observed in Fig. 14b, the moving average of the annual citation ratio is increasing in the past 5 years. The absolute value of the annual citation ratio, however, remains quite fluctuating.

JOMA is actively publishing articles related to Maritime Social and Labour Governance after 2013. Further, citations of these corresponding articles have also increased after 2014.

Comparing Figs. 15a and b, we conclude that, even though the number of citations received by MSLG articles, the number of citations received relative to the number of articles published is still quite low. It is also observed that the moving average line is almost horizontal (indicating that this area is not receiving a high number of citations per articles annually) and it decreases in 2013. 

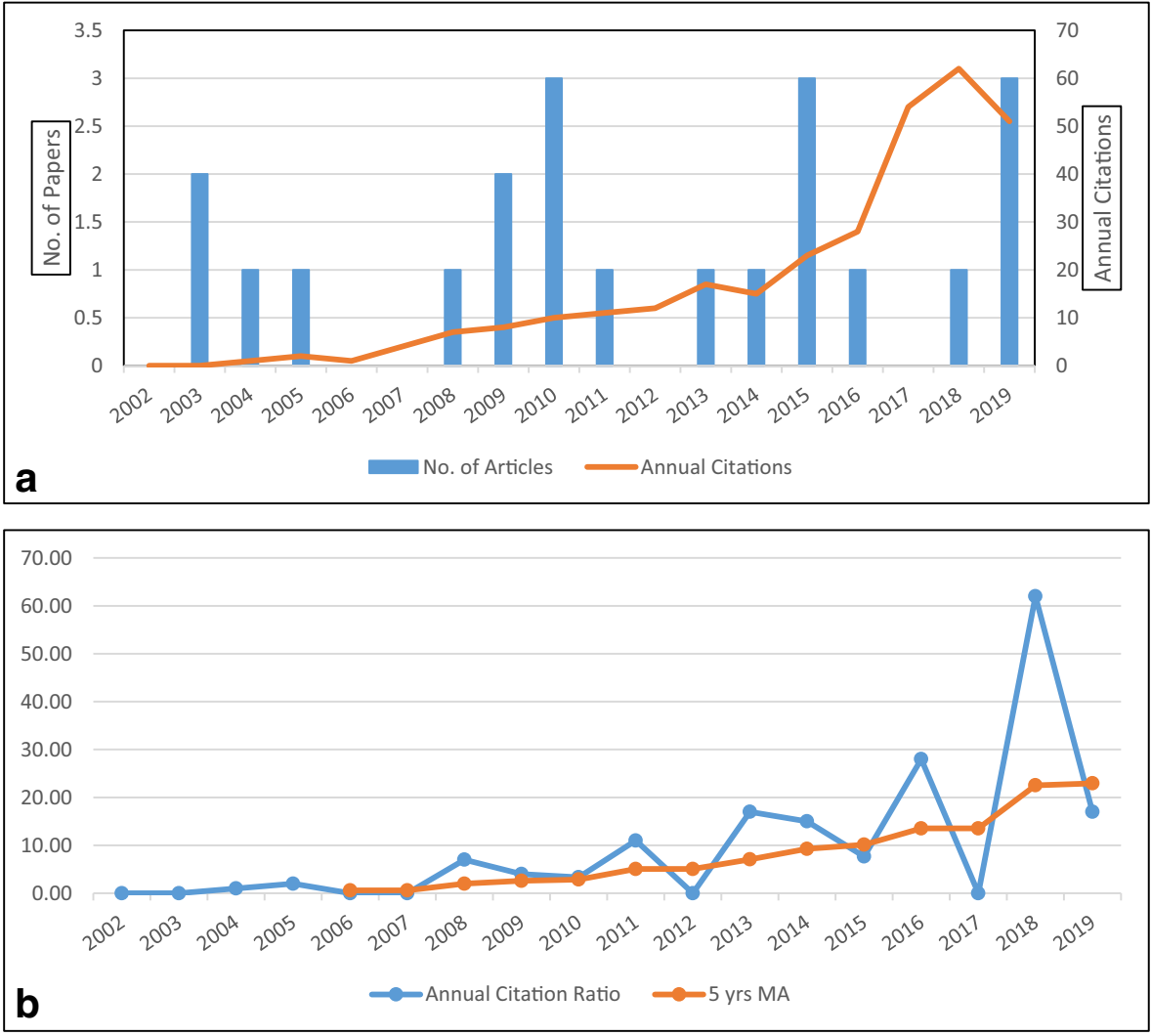

Fig 17 a No. of articles published and annual citations for MET articles. b Annual citation ratio and 5-yearmoving average for MET articles

Figure 16a indicates that JOMA scarcely publishes articles related to Maritime and Marine Technology and Innovation. Further, the citations received by those articles are also quite low, indicating that researchers rarely follow technology and innovation articles published in JOMA.

It can also be seen that the annual citation ratio and its moving average of MMTI articles published at JOMA are quite low, validating the point that JOMA is rarely considered as maritime technology and innovation journal (Fig. 16b).

Maritime Education and Training articles are quite often published in JOMA (as seen in Fig. 17a). It is also quite interesting to see that the annual citation of MET related articles have continuously increased over time. ${ }^{4}$ Fig. $17 \mathrm{~b}$ also indicates that the moving average of annual citation ratio for MET articles has a gradual but continuous growth indicating that JOMA has a growing impact on maritime education and training.

For a holistic understanding of citations received across various research areas, we have created the moving average of the annual citation ratio in a single framework (presented in Fig. 18). It is observed that even though the moving average graph of all different research areas starts close to zero in 2006, their growth over time is different

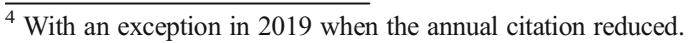




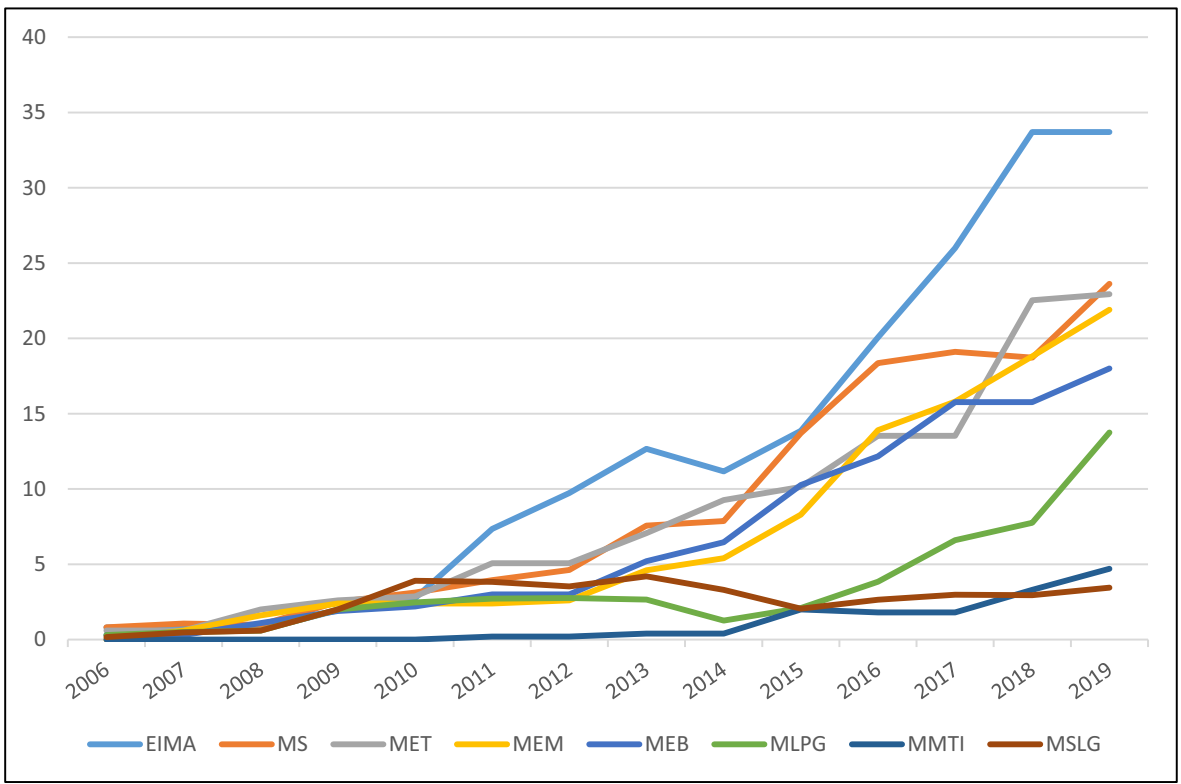

Fig. 18 Five-year-moving average of annual citation ratio for all the RPAs

from each other. The Environmental Impact of Maritime Activities (EIMA) and Maritime Safety (MS) are the two leading areas receiving the highest citations per article published over time. Maritime Education and Training (MET) and Maritime Energy Management (MEM) articles published in JOMA follow EIMA and MS in getting academic attention and citations. Though the moving average of Maritime Economics and Business (MEB) and Maritime Social and Labour Governance (MSLG) has steady growth, relative to other areas, they only lie in the third quartile ranking. Maritime and Marine Technology and Innovation (MMTI) and Maritime Social and Labour Governance (MSLG) articles have not gained any significant attention as per the number of citations.

\section{Conclusion}

This study provides a reflection on JOMA's aims from the perspective of its original mission for the maritime field and offers some insights into its holistic picture to represent the maritime field in a broad term. To support the reflections, a bibliometric analysis of JOMA articles was conducted to aid in assessing its past performance and achievements, as well as identifying new directions for future volumes. It was found that JOMA has been traditionally well aligned with eight RPAs. While such research areas as Maritime Safety, Maritime Education and Training, Maritime Law, Policy and Governance, and Environmental Impact of Maritime Activities have traditionally accounted a large share of JOMA's articles, the Journal has managed to keep a tradition of not letting one area of research dominate over the others from a holistic perspective. As part of the bibliometric analysis the 'Citation Efficiency Factor' was developed as a means of determining which areas of research should be further developed in future 
volumes. The findings indicate that, while all those areas of Environmental Impact of Maritime Activities (EIMA), Maritime Safety (MS), Maritime Education and Training (MET), Maritime Energy Management (MEM), Maritime Economics and Business (MEB), and Maritime Law Policy and Governance (MLPG) remain and sustain a healthy trend in terms of annual citations, there exists a room for improvement in the areas of the Maritime and Marine Technology and Innovation (MMTI) and Maritime Social and Labour Governance (MSLG).

\section{References}

Mazaheri A, Montewka J, Kujala P (2014) Modeling the risk of ship grounding: a literature review from a risk management perspective. WMU J Marit Aff 13(2):269-297

Psaraftis HN (2002) Maritime safety: to be or not to be proactive. WMU J Marit Aff 1(1):3-16

Psaraftis HN, Kontovas CA (2009) CO2 emission statistics for the world commercial fleet. WMU J Marit Aff $8(1): 1-25$

Publisher's note Springer Nature remains neutral with regard to jurisdictional claims in published maps and institutional affiliations. 